http://jmscr.igmpublication.org/home/ ISSN (e)-2347-176x ISSN (p) 2455-0450

crossref DOI: https://dx.doi.org/10.18535/jmscr/v8i5.92

\title{
Effectiveness of Microvascular Decompression for Trigeminal Neuralgia: A Single Institute's Experience with review of Literature
}

\author{
Authors \\ Dr Poonia Nemichand, MS, MCH Neurosurgery ${ }^{1}$, \\ Dr Jain Surendra, MS, MCh Neurosurgery ${ }^{2 *}$ \\ ${ }^{1}$ Professor and Director Neurocare Hospital, Jaipur \\ ${ }^{2}$ Assistant Professor, S M S Medical College, Jaipur \\ Department of Neurosurgery, Neurocare Hospital, Jaipur \\ *Corresponding Author \\ Dr Surendra Jain \\ S M S Medical College, Jaipur, India
}

\begin{abstract}
Background: Trigeminal neuralgia (TN) is characterized by idiopathic sharp, shooting, electric shock like, episodic facial pain along the sensory distribution of the fifth cranial nerve, lasting several seconds, with pain free intervals between attacks. Although many patients respond to the medical line of treatment but when symptoms become intractable and could not tolerate the medications have to go for surgical decompression. Our study aims to review about micro vascular decompression for trigeminal neuralgia and its outcome along with the review of literature.

Methods: It is a retrospective study conducted on 54 cases who were diagnosed with TN between the period of July 2013 to December 2017. Microvascular decompression (MVD) has been performed on all the patients. Demographic data, clinical presentation, surgical findings, complications and long term follow-up were reviewed.

Results: The median age of onset of TN is 50.4 years divided into five age groups ranging from 30 to 79 years with female preponderance showing $59.25 \%$ as compared to males. The distribution of location was in the ratio of right to left was 1.7:1. There was one mortality in our study with 4 patients reporting complications, 1 patient had facial numbness, 1 patient had facial palsy, 1 patient had SAH and 1 patient had CSF rhinorrhoea which resolved after re-exploration of wound and mastoid cell repair. All the patients had satisfactory improvement (post-operative Barrow score of $\leq 3$ ).

Conclusions: To conclude micro vascular decompression (MVD) is the surgical procedure of choice for the treatment of TN who is fit for surgery. Among the currently available surgical methods MVD provides the highest rate of long term satisfaction for the patients and offers the lowest rate of pain recurrence.

Keywords: Microvascular decompression, Trigeminal neuralgia, Facial pain.
\end{abstract}

\section{Introduction}

Trigeminal neuralgia (TN) is a disorder characterized by sudden sharp, shooting, lancinating pain localized to one or two branches of the trigeminal nerve with attacks lasting several seconds to minutes. Most commonly the second 
and third branches of the trigeminal nerve are affected. Paroxysms of pain may be related to tactile stimuli such as hair combing, shaving or a cold wind against the patients face.

These attacks can either begin spontaneously or precipitated by stimulation of so-called trigger zones. The classic episodes of shooting pain are interrupted by pain-free intervals with remissions occasionally lasting for years. ${ }^{[1]}$ The estimated annual incidence of TN is 4 to 5 per $100,000^{[2,3]}$ or even higher, ${ }^{[4]}$ with peak incidence between the ages of 50 and 60 . The vast majority of TN cases are due to microvascular compression of the root entry zone of the trigeminal nerve by vascular structures. ${ }^{[5]} \mathrm{TN}$ is seen with increased frequency in patients suffering from Multiple Sclerosis (MS), where it has an estimated prevalence of $1 \%$ $6.3 \%$, and in MS patients the condition may be bilateral. ${ }^{[6,7]} \mathrm{TN}$ may also occur secondary to space occupying lesions at the cerebello-pontine angle such as epidermoid cyst, meningiomas or vestibular schwannoma. ${ }^{[8]}$

\section{Pathophysiology}

Dandy describe the pathophysiology of trigeminal neuralgia and proposed vascular compression at the root of the trigeminal nerve as the main etiology, causing demyelination and ephaptic transmission. ${ }^{[9,10]}$

In the brain stem the oligodendroglia are responsible for axonal isolation, and outside brain stem is Schwann cells. The transition zone is called Redlich-Obersteiner's zone. Thus at this point, there is a transition from oligodendrocytes myelin to Schwann cell myelin. In this area a number of axons have a marginal or no isolation at all. Lack of isolation could leads to a strengthening effect on input (or output). This transmission, promoted by the vascular compression, leads to increased central stimulation, or to increased activity in the central neuron. Sensory neurons of the faces are often hyperexcited when damage occurs in the nerve and this leads to spontaneous generation of electrical impulses at the damaged spot. ${ }^{[11-14]}$ The chronic vascular compression of the trigeminal nerve has focal demyelination effect which leads to dysfunction of local inhibitory interneurons and development of ectopic neuronal pacemakers. The combination of increased input by afferents ectopic pacemakers and the dysfunction of the intersegmental inhibitory neurons lead to hyperactivity of the nucleus of the trigeminal nerve. The result is TN attacks after stimulation of trigger points supplied by trigeminal nerve during washing, tooth brushing, eating, or even by touching the face.

The diagnosis of TN is primarily on the basis of a history of presenting symptoms. The typical lancinating pain in one or more of the branches of the trigeminal nerve, a typical course in time, and one or more typical pain triggers are essential for diagnosing TN. In typical TN, on examination no neurological deficit is found in trigeminal nerve distribution. This distinguishes typical from atypical TN; the latter is described as a burning and continuous pain (neuropathy)

The purpose of this study was to evaluate the various points related to TN and role of MVD as a better treatment option in medically refractory cases of Trigeminal neuralgia.

\section{Methods}

We retrospectively reviewed records and operative notes of patients who underwent MVD by the senior author for TN between July 2013 and December 2017.

These cases were selected from Neurocare hospital jaipur. Irrespective of age and gender, all the patients diagnosed with $\mathrm{TN}$ involving Ophthalmic, mandible or maxillary branches of trigeminal nerve were operated via retro mastoid approach and micro vascular decompression was carried out.Patients having TN due to secondary causes or in association withother neuropathy were excluded. An informed written consent was obtained from all patients.

The relevant records were reviewed and the demographic information (age, gender and address) along with clinical presentation and 
radiological findings on pre-operative MRI were recorded. Operative records were analyzed to obtain the operative findings and details of the operative procedure. Post-operative records were analyzed and findings recorded. Descriptive statistics were calculated for variables included demographics (age, gender), site of pain (right or left) and distribution of nerve involvement. Operative results were assessed by clinical follow up and periodic phone surveys were done which ranged from 18 months to 60 months with mean of 33.9 months of follow up.

\section{Surgical Technique}

Under general anesthesia, exploration of the cerebellopontine angle was performed through a small, keyhole type (about $2 * 2 \mathrm{~cm}$ diameter) retromastoid craniectomy with patients in the supine position with the head rotated to the side opposite the neuralgia. The margins of transverse sinus and sigmoid sinuses were exposed and the dura was opened along the line bisecting their angle. The fifth cranial nerve was exposed through a supra-cerebellar approach, thus avoiding lateral retraction of the cerebellar hemisphere and traction of the VII-VIII complex of cranial nerves. The microscopic view was transferred to visualize the trigeminal nerve. The arachnoids surrounding the fifth nerve were opened sharply and the whole length of the fifth nerve from the root entry zone to the Meckel cave was carefully explored. Mannitol was not used before dural opening to avoid anatomical modification. In approaching the trigeminal nerve, care was taken to spare petrous veins. The nerve was cautiously dissected free without unnecessary manipulation. Any compressive arteries were relocated away from the trigeminal nerve and its root entry zone in the pons by the use of small pieces of gelfoam.

\section{Results}

A total of 54 patients of TN underwent surgical procedure at Neurocare hospital, Jaipur from July
2013 to December 2017 via retro mastoid approach and MVD.

The patients were stratified into five groups according to age (Table 1).

$55.55 \%(\mathrm{n}=30)$ patients were found to be in 3rd group (41-60 years). There was no patient aged less than 20 or more than 80 years. The mean age of patient's was 50.4 years.

Age at Onset

This ranged between 30 to 79 years, with a mean age of 53.03 years. The peak incidence was in the fifth and sixth decades of life.

Table 1: Age distribution of patients with TN

\begin{tabular}{|l|c|c|}
\hline Age in years & $\begin{array}{r}\text { No of patients (n) } \\
\text { Total 54 }\end{array}$ & Percentage (\%) \\
\hline$<20$ & 0 & 0.0 \\
\hline $21-40$ & 9 & 16.66 \\
\hline $41-60$ & 30 & 55.55 \\
\hline $61-80$ & 15 & 27.77 \\
\hline$>80$ & 0 & 0.0 \\
\hline
\end{tabular}

\section{Gender}

Females comprised $59.25 \%(\mathrm{n}=32)$ of the patients and $40.75 \% \quad(n=22)$ were male, representing a ratio of $1.4: 1$, reflecting an elevated risk for female subjects.

\section{Site of Involvement}

Of the remaining 54 cases, 34 patients (62.96 per cent) suffered excruciating pain on the right side of the face, and 20 patients (37.04 per cent) on left side. This gave a site ratio of 1.7:1 confirming a predominance of right side facial affliction. The right to left side ratio is $1.7: 1$. (Table 2)

Table 2: Side involvement of TN

\begin{tabular}{|c|c|c|}
\hline Side & \multicolumn{2}{|c|}{ No of patients (n) } \\
\hline Right & 34 & $62.96 \%$ \\
\hline Left & 20 & $37.04 \%$ \\
\hline Total & 54 & 100 \\
\hline
\end{tabular}

Branch Involvement The branch distribution to which pain was referred was: V1 only, one case (1.85\%); V2 only, 3 cases (5.55\%); V3 only, no cases; V1 and V2, 5 cases (9.25\%); V2 and V3, 38 cases $(70.37 \%)$; and $\mathrm{V} 1, \mathrm{~V} 2$, and $\mathrm{V} 3,7$ cases (12.96\%).(Table 3) 
Table 3: Branch Involvement

\begin{tabular}{|l|c|c|}
\hline Branch involvement & No of patients & Percentage \\
\hline V1 ONLY & 1 & $1.85 \%$ \\
\hline V2 ONLY & 3 & $5.55 \%$ \\
\hline V3 ONLY & 0 & $0 \%$ \\
\hline V1V2 ONLY & 5 & $9.25 \%$ \\
\hline V2V3 ONLY & 38 & $70.37 \%$ \\
\hline V1V2V3 & 7 & $12.96 \%$ \\
\hline
\end{tabular}

\section{Duration of Preoperative Symptoms}

Duration of preoperative symptoms ranged between 2 months and 17 years (mean 44 months) (Table 4).

Table 4: Duration of preoperative symptoms

\begin{tabular}{|l|c|c|}
\hline $\begin{array}{l}\text { Duration of symptoms } \\
\text { (years) }\end{array}$ & No of patients & Percentage \\
\hline Up to 1 year & 6 & $11.12 \%$ \\
\hline >1 year to 2 years & 12 & $22.22 \%$ \\
\hline >2 years to 3 years & 16 & $29.62 \%$ \\
\hline >3 years to 4 years & 6 & $11.12 \%$ \\
\hline > 4 years & 14 & $25.92 \%$ \\
\hline
\end{tabular}

\section{Preoperative Treatment}

All the patients had a trial of medical treatment, failure which they were offered the option of MVD. Carbamazepine (CBZ) and phenytoin were the most commonly used medicine either alone or in conjunction with $\mathrm{BZ}$ being the first choice. Others medications used include clonazepam, lamotrigene, valproic acid, gabapentin and baclofen. One patient had undergone a failed attempt of glycerol rhizolysis using anhydrous $(99.5 \%)$ glycerol and mvd done after one year of procedure.

\section{Preoperative Status}

All patients underwent MRI brain with FIESTA sequence. All patients were operated by the senior author. Barrow Neurological Institute pain score was calculated for all patients.(Table 5) Preoperatively nine $(16.67 \%)$ patients had a score of 5 , forty-three $(79.62 \%)$ had a score of 4 . Pre operatively 7 patients had DM and 16 patients had HTN.

Postoperatively, at last clinic follow up, two (3.70\%) had a score of 3, five $(9.25 \%)$ had a score of 2 and fourty six (85.18\%) had a score of 1 . A post-operative Barrow score of $\leq 3$ was considered a satisfactory outcome. Post-operative anticonvulsant were given to all the patients for 15 days and suture removal was done on postoperative days 8 .

Table 5: Barrow Neurological Institute Pain Score

\begin{tabular}{|l|l|}
\hline SCORE & Pain Description \\
\hline I & Pain free, no medication \\
\hline I I & Occasional pain, no medication required \\
\hline I II & Some pain, adequately controlled by medication \\
\hline IV & $\begin{array}{l}\text { Some pain, not adequately controlled by } \\
\text { medication }\end{array}$ \\
\hline V & Severe pain or no pain relief \\
\hline
\end{tabular}

Post OP Complication- Fortunately the complication rate was on the lower side in this series with most of them being minor complications (table 6) except one mortality. One patient had CSF rhinorrhoea, which resolved after re-exploration of wound and mastoid cell repair.

Table 6: Post Operative Complication

\begin{tabular}{|l|c|}
\hline Complication & Number( \%) \\
\hline Death & 1 \\
\hline Facial palsy & 1 \\
\hline Csfrhinorrhoea & 1 \\
\hline Facial numbness & 1 \\
\hline SAH & 1 \\
\hline Wound infection & 0 \\
\hline Hearing loss & 0 \\
\hline
\end{tabular}

\section{Discussion}

Trigeminal neuralgia is one of the most unbearable pain producing condition. Currently, many treatment modalities are available such as thermocoagulation, balloon compression, glycerol gangliolysis, radiosurgical techniques , medical treatment and microvascular decompression. These treatments are performed widely, being more noninvasive and safer than posterior fossa exploration. However, there is considerable evidence to prove that neurovascular conflict plays a significant role in the pathogenesis of TN and MVD is the sole technique that directly addresses the presumed etiology of TN.

The theory of vascular compression as the cause of TN is supported by clinical and anatomical evidence. $^{[14,15]}$ In $\mathrm{TN}$ nerve compression is by a vessel as it exits the medulla oblongata, this theory is supported by the success of MVD in the treatment of compression of trigeminal nerve. ${ }^{[16]}$ 
TN usually begins as a relapsing disease with pain-free intervals, which sometimes can last for months or years. These pain-free intervals become shorter until they eventually disappear. With the disease progression, patients may have trouble in talking, eating, face washing, and teeth brushing because of pain caused by these activities. Current treatment usually begins with medications for example, carbamazepine, which fortunately gives an improvement of symptoms. But unfortunately, long-term effect is less effective. It is difficult to continue these drugs because of the many side effects they have, such as hyponatremia. ${ }^{[17]}$

Average age in our study is 53.03 years with peak incidence in the 5th and 6th decade of life, whereas it is almost same as compared to other similar studies.

Female to male ratio is $1.4: 1$ which is similar to other studies with a female to male ratio ranging from $2: 1$ to $4: 3$ several similar studies showed. ${ }^{[18,19]}$

Right side of face is more affected in our series (Right to left 1.7:1). This is similar to other studies.

In our study pain was located mainly in v2 and v3 innervated region $(70.37 \%)$ followed by v1 v2 v3 region (12.96\%).

The average age at surgery was 53.03 years with trigeminal neuralgia symptoms duration of 44.48 months.

In our study, most common source of nerve compression was superior cerebellar artery followed by anterior inferior cerebellar artery and veins in a minority of cases. The average follow up duration was 33.96 month.

Direct comparisons between various studies are tabulated in table 7 (Table 7)

Table 7: Comparisons between Various Studies

\begin{tabular}{|l|c|c|c|c|c|c|}
\hline STUDY & PERIOD & N(M:F) & $\begin{array}{c}\text { DURATION } \\
\text { MO }\end{array}$ & AGE, YR & $\begin{array}{c}\text { SUCCESS } \\
\text { RATE }\end{array}$ & $\begin{array}{c}\text { FOLLOW UP } \\
\text { MO }\end{array}$ \\
\hline Broggi(2000)[28] & $1990-1998$ & $146(75: 71)$ & 24 & 56 & $85 \%$ & 38 \\
\hline Delitala(2001)[29] & $1996-2001$ & $34 \mathrm{NR}$ & 82 & 62.5 & $87.5 \%$ & 24.7 \\
\hline Sindou(2002)[30] & $1979-2002$ & $579(273: 306)$ & 76.8 & 60 & $76.1 \%$ & 96 \\
\hline Ishikawa(2002)[31] & $1997-2000$ & $53 \mathrm{NR}$ & $\mathrm{NR}$ & 63.4 & $84.9 \%$ & $6-30$ \\
\hline Kalkanis(2003)[32] & $1996-2000$ & $1326 \mathrm{NR}$ & $\mathrm{NR}$ & 57 & NR & NR \\
\hline Li(2004)[33] & $2000-2002$ & $62(19 ; 43)$ & 4.4 & 63.6 & $51.6 \%$ & 13 \\
\hline Pamir(2006)[34] & $1986-2004$ & $90(48 ; 42)$ & 7 & 59 & $96.7 \%$ & 12 \\
\hline Sindou(2009)[35] & $1983-1999$ & $330 \mathrm{NR}$ & 8.2 & $28-84$ & $80 \%$ & 98.4 \\
\hline Sandell(2008)[36] & $1999-2005$ & $135(64 ; 71)$ & 5 & 65 & $77.3 \%$ & 38 \\
\hline Bond(2010)[37] & $1994-2009$ & $119(61 ; 58)$ & NR & 60 & $90 \%$ & 39.6 \\
\hline Hong(2011)[38] & $2008-2009$ & $15(1 ; 14)$ & 5.2 & 55.6 & $60 \%$ & 19 \\
\hline Zhong(2011)[39] & $2007-2009$ & $9(5 ; 4)$ & $3-20$ & 60 & $77.8 \%$ & $3-30$ \\
\hline Koopman(2011)[40] & $2002-2004$ & $87 \mathrm{NR}$ & NR & 65.8 & NR & 12 \\
\hline Sandel(2013)[41] & $1999-2009$ & $243(98 ; 145)$ & 7.3 & 63.1 & $90.3 \%$ & 71 \\
\hline Our study & $2013-2017$ & $54(32 ; 22)$ & 44 & 53.03 & $85.18 \%$ & 33.96 \\
\hline
\end{tabular}

Microvascular decompression was first performed by Gardner. ${ }^{[20]}$ Thereafter, Jannetta, ${ }^{[21]}$ using microsurgical techniques, popularized the procedure and named it. It can provide the longest-lasting pain relief and the lowest rates of complication. The patients always acquire immediate improvement or relief after the procedure of MVD, an occurrence as high as $95 \%$ to $97 \%$. Meanwhile, it confers the best long-term outcome. In the largest outcome study to date, a series of 1204 patients by Barker et $\mathrm{al}^{[22]}$ with a mean follow-up period of 6.2 years, $70 \%$ were reported as an excellent, final result, requiring no medication to remain pain-free. The percentage of patients lost to follow-up was $13 \%$. After the follow-up for a mean of 8.2 years, Sindou et $\mathrm{al}^{[23]}$ reported that the percentage to remain pain-free was $80 \%$ in a series of 330 patients. (Table 7) In our study success rate was $85.18 \%$ with mean follow up period of 33.96 month success rate was 
defined as complete pain relief (barrow Neurological Institute Pain Score 1)

The excellent result of MVD for TN has been proven in large studies in the literature; however, a majority of neurosurgeons provided percutaneous or radiosurgical procedures for elderly patients on account of the risks of craniotomy. Literature ${ }^{[24,25]}$ evaluation of the alternative percutaneous procedures, including percutaneous radiofrequency thermocoagulation (PRT), percutaneous balloon compression, and percutaneous glycerol gangliolysis, revealed that PRT, related to the best short- and long-term outcome, was the more favorable choice than percutaneous balloon compression and percutaneous glycerol gangliolysis. However, studies comparing the efficacy of MVD with PRT showed that MVD is superior to PRT. In a comparison between MVD and PRT, Burchiel et $\mathrm{al}^{[26]}$ reported that 1-year pain-free rate was $90 \%$ and $65 \%$, respectively. Tronnier et $\mathrm{al}^{[27]}$ compared the long-term outcome of MVD in 225 patients with that of PRT in 206 patients. The 2-year painfree rate with MVD was $76.4 \%$, compared with $50 \%$ with PRT.

According our study MVD is an effective treatment option in patients with $\mathrm{TN}$ refractory to medical treatment with less complication and good pain relief.

\section{Conclusion}

We conclude that micro vascular decompression (MVD) is the surgical procedure of choice, for young and elderly patients alike for the treatment of medically refractory $\mathrm{TN}$ who are fit to undergo surgery. MVD when done by an experienced surgeon can lead to pain relief with acceptable complication rates. MVD addresses the pathology at the root site of lesion and is the best available modality being a nerve sparing technique as compared to Rhizolysis and radio frequency ablation. Of all the currently available surgical methods MVD provides the highest rate of long termpain relief and satisfaction for the patients with the lowest rate of recurrence.

\section{References}

1. Dandy WE. Concering the cause of trigeminal neuralgia. Am J Surg. 1934; 24:447-55.

2. Merskey H, Bogduk N. Classification of chronic pain, IASP Task Force on Taxonomy. Seattle: IASP Press, 1994

3. Katusic S, Williams D, Beard C, et al. Epidemiology and clinical features of idiopathic trigeminal neuralgia and glossopharyngeal neuralgia: similarities and differences, Rochester, Minnesota, 1945-1984. Neuroepidemiology 1991;10: 276-281

4. MacDonald B, Cockerell O, Sander J, et al. The incidence and lifetime prevalence of neurological disorders in a prospective community-based study in the UK. Brain 2000;123:665-676

5. Zakrzewska JM, Coakham HB. Microvascular decompression for trigeminal neuralgia: update. Curr Opin Neurol 2012;25(3):296-301.

6. Putzki N, Pfriem A, Limmroth V, Yaldizli $\mathrm{O}$, Tettenborn B, Diener $\mathrm{HC}$, et al. Prevalence of migraine, tension-type headache and trigeminal neuralgia in multiple sclerosis. Eur J Neurol. 2009;16 (2):262-7.

7. Nurmikko TJ, Eldridge PR. Trigeminal neuralgia - pathophysiology, diagnosis and current treatment. $\mathrm{Br} J$ Anaesth. 2001;87(1):117-32

8. Cheng TM, Cascino TL, Onofrio BM. Comprehensive study of diagnosis and treatment of trigeminal neuralgia secondary to tumors. Neurology. 1993;43 (11):2298-302.

9. Dandy W. Glossopharyngeal neuralgia (tic doloreaux). Its diagnosis and treatment. Arch Surg. 1927;15:198-214.

10. Pearce JM. Glossopharyngeal neuralgia. Eur Neurol. 2006;55:49-52.

11. Namba S, Shimizu Y, Wani T, Fujiwara N. An experimental model of deafferented 
pain in the cat. Appl Neurophysiol. 1985;48(1-6):201-11.

12. Devor M, Seltzer Z. Pathophysiology of damaged nerves in relation to chronic pain. In: Wall PD, Melzack R, editors. Textbook of Pain. 4th ed. London: Churchill Livingstone; 1999: 129-164.

13. Clavin WH, Howe JF, Loeser JD. Ectopic Repetitive Firing in Focally Demyelinated Axon and Some Implication for Trigeminal Region. Amsterdam: Elsevier/North-Holland; 1977: 125-136.

14. Burchiel KJ. Abnormal impulse generation in focally demyelinated trigeminal roots. $\mathrm{J}$ Neurosurg. 1980;53(5):674-83.

15. Hamlyn PJ, King TT. Neurovascular compression in trigeminal neuralgia: a clinical and anatomical study. J Neurosurg. 1992;76(6):948-954.

16. Slavin KV. Glossopharyngeal neuralgia. Semin Neurosurg. 2004;15:71-9.

17. Taylor JC, Brauer S, Espir MLE. Longterm treatment of trigeminal neuralgia with carbamazepine. Postgrad Med J. 1981;57 (663):16-18.

18. Jannetta PJ. Arterial compression of the trigeminal nerve at the pons in patients with trigeminal neuralgia. J Neurosurg. 1967;26(1):159-62.

19. Mendoza N, Illingworth R D. Trigeminal neuralgia treated by microvascular decompression: a long-term follow-up study. Br J Neurosurg. 1995;9(1):13-9.

20. Gardner WJ. Concerning the mechanism of trigeminal neuralgia and hemifacial spasm. J Neurosurg1962; 19: 947- 958 [PubMed]

21. Jannetta PJ. Arterial compression of the trigeminal nerve at the pons in patients with trigeminal neuralgia. $J$ Neurosurg 1967; 26: 159- 162 [PubMed]

22. Barker FG, Jannetta PJ, Bissonette DJ, et al. The long term outcome of microvascular decompression for trigeminal neuralgia. N Engl J Med 1996; 334: 1077- 1083 [PubMed]

23. Sindou M, Leston JM, Decullier E, et al. Microvascular decompression for trigeminal neuralgia: the importance of a noncompressive technique-Kaplan-Meier analysis in a consecutive series of 330 patients. Neurosurgery 2008; 63: 341- 350 [PubMed

24. Cowan JA, Brahma B, Sagher O. Surgical treatment of trigeminal neuralgia: comparison of microvascular decompression, percutaneous ablation, and stereotactic radiosurgery. Techn Neurosurg 2003; 8: 157- 167

25. Taha JM, Tew JM., Jr Comparison of surgical treatments for trigeminal neuralgia: reevaluation of radiofrequency rhizotomy. Neurosurgery 1996; 38: 865871 [PubMed]

26. Burchiel KJ, Steege TD, Howe JF, et al. Comparison of percutaneous radiofrequency gangliolysis and microvascular decompression for the surgical management of tic douloureux. Neurosurgery 1981; 9: 111- 119 [PubMed]

27. Tronnier VM, Rasche D, Hamer J, et al. Treatment of idiopathic trigeminal neuralgia: comparison of long-term outcome after radiofrequency rhizotomy and microvascular decompression. Neurosurgery2001； 48: 1261- 1267 [PubMed

28. Broggi G, Ferroli P, Franzini A, et al. Microvascular decompression for trigeminal neuralgia: comments on a series of 250 cases, including 10 patients with multiple sclerosis. J NeurolNeurosurg Psychiatry 2000;68:59-64

29. Delitala A, Brunori A, Chiappetta F. Microsurgical posterior fossa exploration for trigeminal neuralgia: a study on 48 cases. Minim Invasive Neurosurg 2001; 44:152-156 
30. Sindou M, Howeidy T, Acevedo G. Anatomical observations during microvascular decompression for idiopathic trigeminal neuralgia with correlations between topography of pain and site of the neurovascular conflict). Prospective study in a series of 579 patients. Acta Neurochir (Wien) 2002;144:1-13

31. Ishikawa $M$, Nishi $S$, Aoki $T$, et al. Operative findings in cases of trigeminal neuralgia without vascular compression: proposal of a different mechanism. J ClinNeurosci2002;9:200-204

32. Kalkanis SN, Eskandar EN, Carter BS, et al. Microvascular decompression surgery in the United States, 1996 to 2000: mortality rates, morbidity rates, and the effects of hospital and surgeon volumes. Neurosurgery 2003;52:1251-1262

33. Li S-T, Pan Q, Liu N, et al. Trigeminal neuralgia: what are the important factors for good operative outcomes with microvascular decompression. Surg Neurol 2004;62:400-404

34. Pamir M, Peker S. Microvascular decompression for trigeminal neuralgia: a long-term follow-up study. Minim Invasive Neurosurg 2006;49:342-346

35. Sindou M, Leston JM, Decullier E, et al. Microvascular decompression for trigeminal neuralgia: the importance of a noncompressive technique-Kaplan-Meier analysis in a consecutive series of 330 patients. Neurosurgery 2008;63:341-351

36. Sandell T, Eide PK. Effect of microvascular decompression in trigeminal neuralgia patients with or without constant pain. Neurosurgery 2008;63:93-100.
37. Bond AE, Zada G, Gonzalez AA, et al. Operative strategies for minimizing hearing loss and other major complications associated with microvascular decompression for trigeminal neuralgia. World Neurosurg2010;74:172-177

38. Hong W, Zheng X, Wu Z, et al. Clinical features and surgical treatment of trigeminal neuralgia caused solely by venous compression. Acta Neurochir (Wien) 2011;153:1037-1042

39. Zhong J, Zhu J, Li S-T, et al. Microvascular decompressions in patients with coexistent hemifacial spasm and trigeminal neuralgia. Neurosurgery 2011; 68:916-920

40. Koopman JS, de Vries LM, Dieleman JP, et al. A nationwide study of three invasive treatments for trigeminal neuralgia. Pain 2011;152:507-513

41. Sandel T, Eide PK. Long-term results of microvascular decompression for trigeminal neuralgia and hemifacial spasms according to preoperative symptomatology. Acta Neurochir (Wien) 2013;155: 1681-1692. 